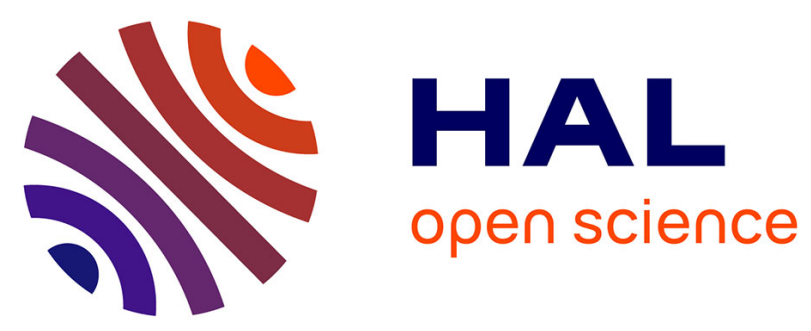

\title{
Percolation and superconductivity in ion-implanted aluminium films
}

Frédéric Meunier, P. Pfeuty, A.M. Lamoise, J. Chaumont, H. Bernas, C. Cohen

\section{To cite this version:}

Frédéric Meunier, P. Pfeuty, A.M. Lamoise, J. Chaumont, H. Bernas, et al.. Percolation and superconductivity in ion-implanted aluminium films. Journal de Physique Lettres, 1977, 38 (21), pp.435-437. 10.1051/jphyslet:019770038021043500 . jpa-00231414

HAL Id: jpa-00231414 https://hal.science/jpa-00231414

Submitted on 1 Jan 1977

HAL is a multi-disciplinary open access archive for the deposit and dissemination of scientific research documents, whether they are published or not. The documents may come from teaching and research institutions in France or abroad, or from public or private research centers.
L'archive ouverte pluridisciplinaire HAL, est destinée au dépôt et à la diffusion de documents scientifiques de niveau recherche, publiés ou non, émanant des établissements d'enseignement et de recherche français ou étrangers, des laboratoires publics ou privés. 
Classification

Physics Abstracts

$61.70 \mathrm{~T}-71.30-73.60 \mathrm{~K}$

\title{
PERCOLATION AND SUPERCONDUCTIVITY IN ION-IMPLANTED ALUMINIUM FILMS $\left(^{*}\right)$
}

\author{
F. MEUNIER and P. PFEUTY \\ Laboratoire de Physique des Solides, Université Paris XI, 91405 Orsay, France.

\section{A. M. LAMOISE (**) and J. CHAUMONT} \\ Laboratoire René-Bernas du Centre de Spectrométrie Nucléaire et de Spectrométrie de Masse, \\ BP no 1, 91406 Orsay, France
}

\section{H. BERNAS}

Institut de Physique Nucléaire, BP no 1, 91406 Orsay, France

\section{COHEN}

Groupe de Physique des Solides de 1'E.N.S., Université Paris VII, 2, place Jussieu, 75223 Paris, France

(Reçu le 8 juillet 1977, accepté le 23 septembre 1977)

\begin{abstract}
Résumé. - L'implantation ionique de $\mathrm{Si}$ et Ge dans des films minces d'aluminium à $8 \mathrm{~K}$ conduit à des alliages dont la température critique supraconductrice est fortement augmentée (jusqu'à $8,35 \mathrm{~K}$ pour $\mathrm{Al}_{60} \mathrm{Si}_{40}$ ), et qui présentent une transition métal-non métal pour une concentration en volume de $45 \% \mathrm{Si}$. Ces résultats sont comparés à ceux obtenus par ailleurs pour des films préparés par évaporation à froid.
\end{abstract}

\begin{abstract}
Ion implantation of $\mathrm{Si}$ and $\mathrm{Ge}$ in $\mathrm{Al}$ thin films at $8 \mathrm{~K}$ produces alloys exhibiting enhanced superconducting transition temperatures (up to $8.35 \mathrm{~K}$ for $\mathrm{Al}_{60} \mathrm{Si}_{40}$ ) and a metal-non metal transition at a volume concentration of $45 \% \mathrm{Si}$. These results are compared to those obtained by other authors on films prepared by evaporation on cold substrate.
\end{abstract}

The electrical conductivity of thin films has recently received renewed attention [1], largely because of its relation to percolation and phase transition problems. Most of the existing information is based on studies of samples prepared by splat-cooling from the melt [2], by sputtering [3], or by coevaporation on cold substrates [4]-[6]. Such samples are generally unstable alloys of a metal and semi-conductor or oxide, and the interpretation of experimental results depends rather critically on assumptions concerning their microscopic structure. Specifically, a granular structure (small metallic grains separated by semiconducting or insulating barriers) has been invoked to account for spectacular increases in the superconducting transition temperature $T_{\mathrm{c}}$ of several such alloys [2], [5], [6] : Josephson tunnelling was suggested to

${ }^{*}$ ) Work supported by D.G.R.S.T. under Contracts 74.7 .1083 and 76.7.0936.

$\left({ }^{* *}\right)$ Present address : Société Nationale des Industries Aérospatiales, B.P. 84, 92320 Châtillon, France. account for overall superconductivity [5], [7], and excitonic [8] or surface plasmon [9] effects were suggested to account for $T_{\mathrm{c}}$ enhancements. In this Letter, we report results from a different approach to the problem. Ion implantation at liquid helium temperatures allows us to introduce chosen impurities into thin films at reasonably uniform - and large concentrations. Since the implantation is carried out at rather high energies and at temperatures such that no radiation damage annealing takes place, disordering occurs as a result of collisions of the implanted ion with host atoms. We have compared resistivity and superconductivity results on such systems with those obtained from films with nominally similar compositions, prepared by more classical methods. We find a metal-non metal (MNM) transition for $\mathrm{Al}-\mathrm{Ge}$ and $\mathrm{Al}-\mathrm{Si}$ films at a critical volume concentration of $50 \%$; superconductivity in both systems, with the maximum in $T_{\mathrm{c}}$ at an $\mathrm{Al}$ concentration of $\sim 60$ vol. $\%$; a definite correlation between the composition dependence of $T_{\mathrm{c}}$ and of the normal 
resistivity. These results are strikingly similar to those obtained for granular films [5], except that we find significantly higher maximum superconducting transition temperatures. Our results are discussed in terms of percolation properties, and lead us to suggest that the nature of the disorder in implanted films be examined in detail.

Our low-temperature ion implantation system [10] was briefly described previously [11]. Basically, it consists of a liquid helium post-accelerating lens adapted to the Orsay ion implantor. Under standard conditions, implantation temperatures of $\sim 8 \mathrm{~K}$ are obtained, and resistivity measurements may be carried out automatically after each implantation at temperatures ranging from $1.5 \mathrm{~K}$ to $350 \mathrm{~K}$, using a four-point probe technique. The films (typically $10 \times 0.3 \mathrm{~mm}^{2}$, thickness 500-600 $\AA$ for $\mathrm{Al}$ and $1000-1500 \AA$ for Ge) were evaporated on crystalline quartz substrates. The Al film resistivity ratio $\rho(300 \mathrm{~K}) / \rho(4.2 \mathrm{~K})$ was 3.5-4.0. Size and impurity effects were normalized out by simultaneously measuring the resistivity of the implanted sample and that of an identical film (on the same substrate) shielded from the ion beam. The upper limit of our resistivity-measuring device was $2000 \Omega$.cm, unfortunately preventing a detailed study of the MNM transition.

The measured resistivity is of course a sample average, while the impurity and damage depth distributions [12] are approximately Gaussian for a single implantation energy. In order to improve sample uniformity, implantations were performed at two different energies for $\mathrm{Si}$ (30 and $15 \mathrm{keV}$ ) and $\mathrm{Ge}$ (50 and $25 \mathrm{keV}$ ) in $\mathrm{Al}$, and for $\mathrm{Al}$ (100 and $40 \mathrm{keV}$ ) in Ge. For a given sample, the evolution of the normal resistivity or of $T_{\mathrm{c}}$ was found to depend only on the implanted ion concentration, and not on the sequence of implantations (as long as the sample doping was reasonably uniform). Thus, implantation through a previously implanted layer had no visible effect : this is in contrast to results on $\mathrm{Al}-\mathrm{H}$ [11], and it indicated that our samples are indeed disordered.

The dose-dependence of $T_{\mathrm{c}}$ and of the normal resistivity at $10 \mathrm{~K}\left(\rho_{\mathrm{N}}\right)$ for the Al-Si implanted alloy is presented in figure 1. Similar results are obtained for the Al-Ge system. In order to convert the dosedependence to the alloy composition-dependence also shown in figure 1 , three phenomena must be properly accounted for : (i) sputtering [13] of the implanted film by the incoming beam; (ii) recoilimplantation of surface impurities, i.e., oxygen from the surface oxide layer or light impurities coldtrapped on the sample surface (under our implantation conditions, the latter produces $\sim 4$ atomic layers per hour, and the implantation lasts several hours); and (iii) the possibly high impurity (mainly oxygen) content of the film before implantation. We have assumed that $\mathrm{Al}$ sputtering by $\mathrm{Si}$ is identical to that of $\mathrm{Al}$ by $\mathrm{Al}$ ( 0.3 at/at) [13] and may be neglected. The light impurity-content due to recoil implantation

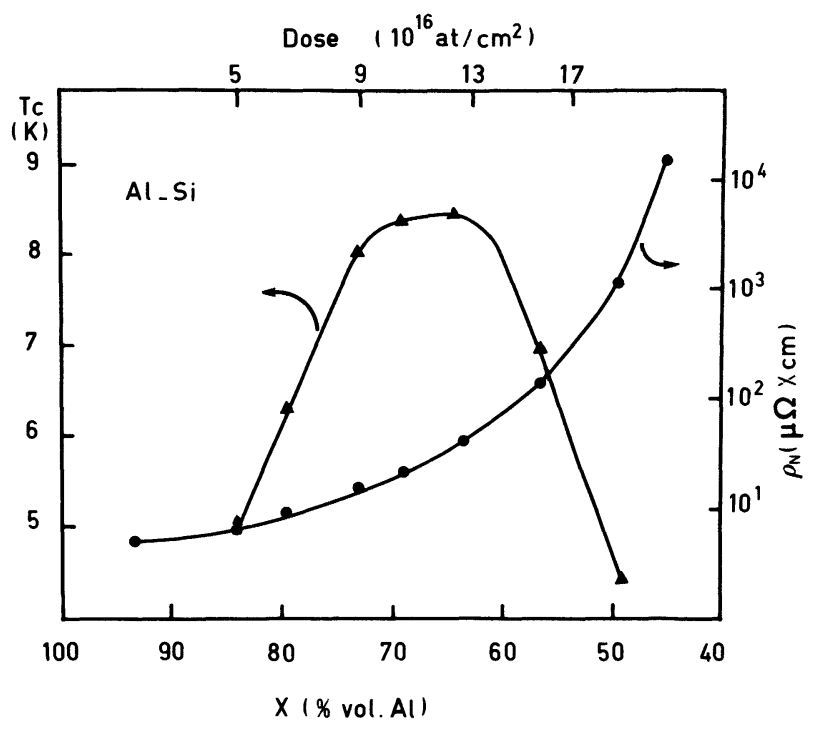

FIG. 1. - Dose and composition dependence of the superconducting transition temperature $T_{\mathrm{c}}$ and of the normal resistivity $\rho_{\mathrm{N}}$ measured at $10 \mathrm{~K}$ for a $\mathrm{Si}$-implanted $\mathrm{Al}$ film.

was calculated [14] to be $<5$ at $\%$ at the highest $\mathrm{Si}$ implanted dose. Rutherford backscattering (RBS) measurements, carried out with a $1.8 \mathrm{MeV}{ }^{4} \mathrm{He}$ beam and a previously described setup [15], revealed that the oxygen impurity content of Al films evaporated on carbon substrates was negligible before and after $\mathrm{Al}$ or $\mathrm{Si}$ implantation. The situation was more complicated for the Al-Ge system because of the high sputtering ratios of $\mathrm{Ge}$ and $\mathrm{Al}$ by $\mathrm{Ge}$, and because of the rather large recoil implantation probability. RBS experiments on $\mathrm{Al}$ and Ge films [16] before and after implantation at varying doses allowed sputtering ratio evaluations from the residual $\mathrm{Al}$ and $\mathrm{Ge}$ content of the films. (Typically, the measured sputtering ratio was $\sim 7$ at/at for $\mathrm{Ge}$ on pure $\mathrm{Ge}, \sim 1$ at/at for $\mathrm{Al}$ by $\mathrm{Ge}$ in $\mathrm{Al}_{0.60} \mathrm{Ge}_{0.40}$ and $\sim 0.1$ at/at for $\mathrm{Ge}$ by $\mathrm{Al}$ at the same composition). These experiments also provided quantitative data on the rather large recoilimplantation effects due to the $\mathrm{Ge}$ ion beam. Within the uncertainties due to these evaluations, the composition-dependence of $\rho_{\mathrm{N}}$ and $T_{\mathrm{c}}$ for Al-Si and Al-Ge were identical. Note that the pertinent parameter in these experiments is not the atomic ratio, but the metal-to-non metal volume ratio $x$. Thus, when the Al volume ratio is $60 \%$ in Al-Ge, the volume concentrations of $\mathrm{Ge}$ and $\mathrm{O}$ are estimated to be respectively $(30 \pm 3) \%$ and $(10 \pm 3) \%$.

For both Al-Si and Al-Ge, the change in the temperature coefficient of the resistivity - i.e., the transition from semiconducting to metallic conductivity occurs when $x \simeq 0.45$ and the normal resistivity at $10 \mathrm{~K}$ is $\sim 10^{4} \mu \Omega . \mathrm{cm}$; the resistivity then decreases sharply when $x \simeq 0.50$ ( $T_{\mathrm{c}}$ corresponding increases); the maximum $T_{\mathrm{c}}$-values are obtained when $x \simeq 0.60$ and $\rho_{\mathrm{N}} \simeq 100 \mu \Omega \mathrm{cm}$. Thus, the highest superconducting temperatures are obtained at extremely high damage levels (typically each atom in the 
Al-Si alloy with $T_{\mathrm{c}}=8.35 \mathrm{~K}$ has been displaced $\sim 100$ times on average). The influence of disorder is emphasized by experiments [17] in which the samples were annealed after low-temperature implantation (thus inducing segregation), and subsequently reimplanted at low temperature : in all cases, disordering was required to maximize $T_{\mathrm{c}}$, and our highest $T_{\mathrm{c}}$ values (respectively $7.35 \mathrm{~K}$ and $8.35 \mathrm{~K}$ for $\mathrm{Al}-\mathrm{Ge}$ and $\mathrm{Al}-\mathrm{Si}$ ) are much higher than those obtained in granular films (6.6 K [6] and $5.5 \mathrm{~K}$ [2] respectively).

The similarity of the composition dependence of $T_{\mathrm{c}}$ and $\rho_{\mathrm{N}}$ in our implanted films (Fig. 1) and in granular structures [1], [5] over the composition range $0.5<x \leqslant 1.00$ strongly suggests that a common interpretation of these results be searched for. In both cases, the semiconducting behaviour observed at $0.45<x<0.5$ is probably due to tunnelling between Al clusters, with a localization threshold [18] at $x \sim 0.45$. The transition at $x \sim 0.5$ may be discussed in terms of percolation conduction [19].

For three-dimensional systems, the theoretically predicted [19] percolation threshold is $x_{\mathrm{c}} \sim 0.3$, far below the value $\left(x_{\mathrm{c}} \sim 0.5\right)$ observed in our implanted systems as well as in granular metals [1] whether or not the latter are annealed. It has been suggested [19] that $x_{\mathrm{c}}$ (just as $T_{\mathrm{c}}$ in phase transition studies) may not be a universal quantity, and could depend on the properties of the metal and the non-metal involved. In view of the variety of systems for which $x_{\mathrm{c}} \sim 0.5$, however, other possibilities should be examined. For example, we note that $\dot{x}_{\mathrm{c}}=0.5$ is the expected critical composition for a two-dimensional system. Since the experiments are performed on thin films (their thickness being some $10^{5}$ times smaller than their planar dimensions), their percolation threshold may lie somewhere between the two- and threedimensional limits [20], as was previously found [21] in the case of phase transitions. Unfortunately, strong variations in the value of $x_{c}$ are only expected for very thin films, whose thickness is of the order of the metallic cluster size (typically $50 \AA$ in granular films), far smaller than that of our films. The problem clearly warrant further study.

Granular films display a percolation structure [1] on a quasi-macroscopic scale (with rather large clusters). The percolation structure of implanted films is much finer : the presence of small grains cannot be excluded, but in view of implantation-induced disorder, their diameter is presumably far smaller (perhaps 10-20 $\AA$ ). It remains to be seen whether these structural differences may explain why the maximum $T_{\mathrm{c}}$ is enhanced in implanted films without any change in the percolation threshold [22]. Structural studies of implanted films (before and after annealing) are needed to resolve this point. Tunnelling experiments on heavily implanted samples, recently [23] shown to be possible, should also provide insight into the origin of the $T_{\mathrm{c}}$ enhancement.

Acknowledgments. - We wish to thank Prof. J. Friedel for enlightening comments, and E. d'Artemare, F. Lalu and M. Salomé for technical assistance.

\section{References}

[1] Abeles, B., Ping Sheng, Coutts, M. D. and Arie, Y., $A d v$. Phys. 24 (1975) 407.

[2] Tsuei, C. C. and Johnson, W. L., Phys. Rev. B 9 (1974) 4742.

[3] Hauser, J. J., Phys. Rev. B 3 (1971) 1611.

[4] BuCKel, W. and Hilsch, R., Z. Phys. 138 (1954) 109.

[5] Abeles, B. and Hanak, J. J., Phys. Lett. 34A (1971) 165.

[6] Fontaine, A. and Meunier, F., Phys. Kond. Mat. 14 (1972) 119.

[7] Deutscher, G., Phys. Lett. 35A (1971) 28.

[8] Allender, D., Bardeen, J., Bray, J., Phys. Rev. B 7 (1973) 1020.

[9] Economou, E. N. and Ngai, K. L., Solid State Commun. 17 (1975) 1155.

[10] LaMoISE, A. M., Thesis, University of Paris XI (1977, unpublished).

[11] Lamoise, A. M., Chaumont, J., Meunier, F., Bernas, H., J. Physique Lett. 36 (1975) L-271 and J. Physique Lett. 36 (1975) L-305.

[12] Winterbon, K. B., Sigmund, P. and Sanders, J. B., Mat. Fys. Medd. Dan. Vid. Selsk. 37 (1970) no 14

[13] Almèn, O. and Bruce, G., Nucl. Instrum. Methods 11 (1961) 257.
[14] Moline, R. A., Reutlinger, E. and North, J. C., Atomic Collisions in Solides, edited by S. Datz, B. Appleton and C. D. Moak (Plenum, N.Y.) 1975.

[15] Abel, F., Amsel, G., Bruneaux, M., Cohen, C., Maurel, B., Rigo, S. and Roussel, J., J. Radio. Chem. 16 (1973) 587.

[16] Ge films were implanted with $\mathrm{Al}$ in order to reach the Ge-rich side of the phase diagram.

[17] Lamoise, A. M., Chaumont, J., Lalu, F., Meunier, F. and Bernas, H., J. Physique 37 (1976) 287.

[18] Thouless, D. J., Phys. Rep. 13 (1974) 93.

[19] Kirkpatrick, S., Rev. Mod. Phys. 45 (1973) 574 and refs. therein.

[20] Pfeuty, P., to be published.

[21] Fisher, M. E., J. Vac. Sci. Technol. 10 (1973) 665.

[22] The large $T_{\mathrm{c}}$ enhancements observed here cannot be ascribed to metallic Si or Ge [STRITZKer, B. and WüHL, H., $Z$. Phys. 24B (1976) 367] since they coexist with an infinite Al cluster.

[23] Dumoulin, L., Nedellec, P., Chaumont, J., Gilbon, D., Lamoise, A. M. and Bernas, H., C. R. Hebd. Séan. Acad. Sci. 283 (1976) 285. 